\title{
CFD Simulation of flow around angle of attack and sideslip angle vanes on a BAe Jetstream 3102 - Part 2
}

\author{
C J Bennett, N J Lawson, J E Gautrey, A Cooke \\ National Flying Laboratory Centre \\ School of Aerospace, Transport and Manufacturing \\ Cranfield University \\ C.J.Bennett@Cranfield.ac.uk
}

\begin{abstract}
A previous study analysing the local flow around angle of attack and sideslip angle vanes on a BAe Jetstream 3102 turboprop is extended to study the additional effects of bank angle. A full matrix of CFD simulations is carried out to investigate how the introduction of a bank angle affects vane performance for a range of flight conditions. An updated calibration method to convert the raw vane readings into true values of angle of attack and sideslip, incorporating a correction factor as a function of the bank angle, is presented. The results are shown to be accurate for a wide range of flight configurations. Uncertainty analysis indicates that raw vanes reading errors should be below $\pm 0.1^{\circ}$ to ensure that total calibration errors are restricted to less than $2 \%$ for angle of attack and $5 \%$ for sideslip angle.
\end{abstract}

\section{INTRODUCTION}

The Jetstream 31 considered for this paper, operated by the National Flying Laboratory Centre (NFLC) at Cranfield University, has undergone major modifications to convert the aircraft into a flying laboratory to be used for research and flight test demonstrations. One modification required the installation of flow angle vanes to the nose section of the airframe. Flow angle vanes are small, mass balanced winglets designed to align with the free stream of air during flight and are by far the most common method for measuring angles of attack and sideslip in civil aviation. For a relatively inexpensive system, accurate results are possible assuming an precise calibration. However, should an aircraft require a flow angle vane modification, no set of bespoke fittings exists for a given aircraft. The vanes are manufactured by a number of companies to be somewhat universal. Furthermore, vanes are not assigned positioning instructions or guidelines for installation. Therefore, the uncorrected vane performance is highly type specific [1]. Intuitively, the furthest convenient forward position on the aircraft will allow the vanes to be exposed to as close to free stream conditions as possible. If the vanes are fitted to the airframe further aft, the influence of the wings, propeller and airframe may considerably impair the vane readings. Ideally, systems measuring flow angles such as the vanes discussed here, differential pressure sensors or probes, and laser tracking systems, should be fitted to a boom usually extended out from the nose of the aircraft, well away from the influence of the airframe on the flow field [2]. However in the case of the Jetstream, the vanes were installed for data gathering purposes and are not safety critical. Therefore, for ease of certification the vanes were fitted to the airframe nose section, see Fig. 1 .

All systems for measuring angle of attack and sideslip mentioned above are susceptible to errors due to a number of external factors as outlined in [3]. This has led to considerable 


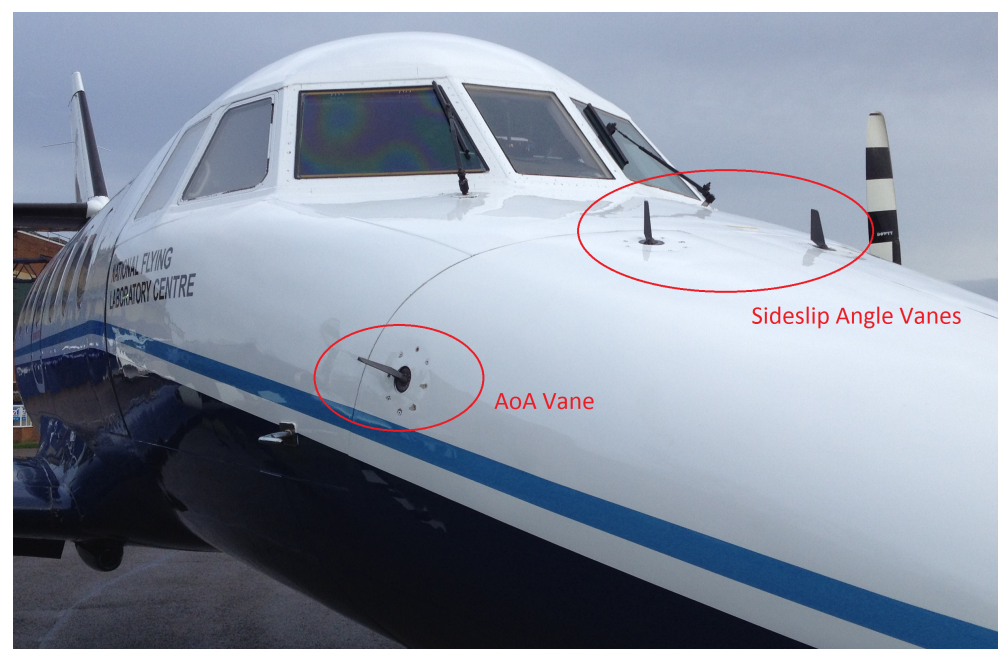

Figure 1: Photograph showing the location of the flow angle vanes on the nose of the Jetstream.

work focused on eliminating these errors with sophisticated calibration techniques. A number of proposed methods for calibration are summarised in [3] including theoretical calculations, Computational Fluid Dynamics (CFD) modelling, wind tunnel and flight testing. Due to the availability of substantial historical flight test data for the Jetstream and significant computational resources, this study will utilise CFD analysis with comparison to flight test data to determine an accurate calibration. Clearly, if a number of calibration techniques are combined, the accuracy of the results and their reliability will be increased.

In the previous study [3], a detailed CFD [4] investigation of the local flow around angle of attack and sideslip angle vanes was carried out for a range of angles of attack and sideslip. Examining the direction of the local flow at the vane locations, it was seen that the readings from the vanes differed considerably depending on the flight configuration of the aircraft. It was shown that the angle of attack vane was affected by the sideslip angle and the sideslip angle vanes were affected by the angle of attack. This behaviour is due to the deflection of the airflow around the nose section of the aircraft. The analysis [3] highlighted significant errors with the calibration method originally implemented following the vanes modification since the effect of sideslip angle on the angle of attack reading and vice versa was not considered. Therefore, a revised calibration method based on the CFD analysis, in conjunction with flight test data, was developed to convert the raw data from the vanes into true readings depending on the angle of attack and sideslip angle, but for zero bank angle in all cases.

In this paper, the aim is to extend the method [3] to include the effect of bank angle. Again, a comprehensive set of CFD simulations are presented, this time with the inclusion of a range of bank angles of up to $\pm 5^{\circ}$, to investigate the effect on the local flow around the vanes and hence the additional errors in the readings which may arise. The aim is to follow similar methodology as in [3], but to derive a revised method to convert the raw vane readings into true values and will include a correction factor as a function of the bank angle. Depending on the parameters known in any given flight condition, the new formulae with corresponding correction factors will facilitate either corrections of the raw angle of attack and sideslip angle vane readings, or a calculation of the bank angle based on the variation of raw vane readings in flight. 


\section{Bank Angle Detection and Correction}

During standard laboratory flights, a number of core parameters including angle of attack, sideslip angle and bank angle are measured simultaneously by a Linton Inertial Reference System (IRS) mounted in the rear of the Jetstream's fuselage. In the past, IRS measurements have been used to correct the raw vane readings for angle of attack and sideslip angle. However, the IRS was shown in [3] to have a $95 \%$ confidence interval of $\pm 1.4^{\circ}$ and hence only allows relatively coarse calculations based on it's measurements. For this reason, the method derived in [3] to convert the raw vane readings into true angles of attack and sideslip depended only on the raw vane readings themselves, eliminating any error introduced by additional independent systems. However, as it will be shown in a later section, the introduction of a bank angle affects both the angle of attack and sideslip angle vanes and so must be monitored separately by the IRS.

In the current set-up, the resolution of the data acquired from standard laboratory flights is restricted by the accuracy of the IRS readings since any errors in the measured data are propagated throughout the correction. By implementing the method derived in this paper, reliance on the IRS readings is reduced, with corrections for bank angle only applied at the final step of the calculation, significantly reducing error in the final output.

Alternative methods and techniques may be used to monitor and record bank angle data. Early methods, such as those outlined in [5] included measurements based on photographs either taken of the aircraft from the ground, or taken from the aircraft of the horizon. Retrospective calculations based on the photographs would yield an accurate bank angle for that particular moment in flight. Although this method is free from errors due to accelerations, it is inherently impracticable since the data is not instantaneously available to the pilot. Furthermore, the reliance on clear visibility means that this method is often unusable, and hence is used rather as a calibration tool for other equipment than a direct measure of bank angle. Reference [5] therefore describes how simple systems on-board the aircraft can be used to measure bank angle based on some predetermined reference. Pendulums and gyroscopes offer one and two degrees of freedom respectively and can yield relatively accurate results in steady state conditions. However, both pendulums and gyroscopes are highly susceptible to aircraft accelerations which can significantly increase error. It was therefore concluded in [5] that although a definitive method for measuring bank angle is by no means established, most accurate results are found when two or more of the methods outlined above are combined.

A more advanced system by way of single laser tracking is described in [6] focused specifically on measuring the bank angle of an aircraft in flight. Although the author notes several companies currently developing laser tracking equipment, this technology and it's application in determining bank angle in particular, is very much in it's infancy and is therefore expensive.

In the Measurement, Instrumentation and Sensors Handbook [7], the authors describe a far more common method for measuring pitch, yaw and roll: an Inertial Measurement Unit (IMU). The IMU's internal accelerometer and gyroscopes are capable of measuring the aircraft's attitude in three dimensions but must be coupled with a barometric altimeter to correct the readings for vertical drift. Although not as complex, the Jetstream's IRS referred to for calculations regarding this paper, works in a similar way.

The IRS readings will therefore provide instantaneous data to correct the output of the calibration first derived in [3] for bank angle variation. Specifically regarding the flow angle vanes and their behaviour and response to various flight conditions, the preceding paper [3] revealed the true angle of attack depended on a cubic polynomial function of the raw angle of attack vane reading and the true sideslip. Similarly, the true sideslip angle can be found based on either of the two raw sideslip vane readings and the true angle of attack. The system of three equations was 


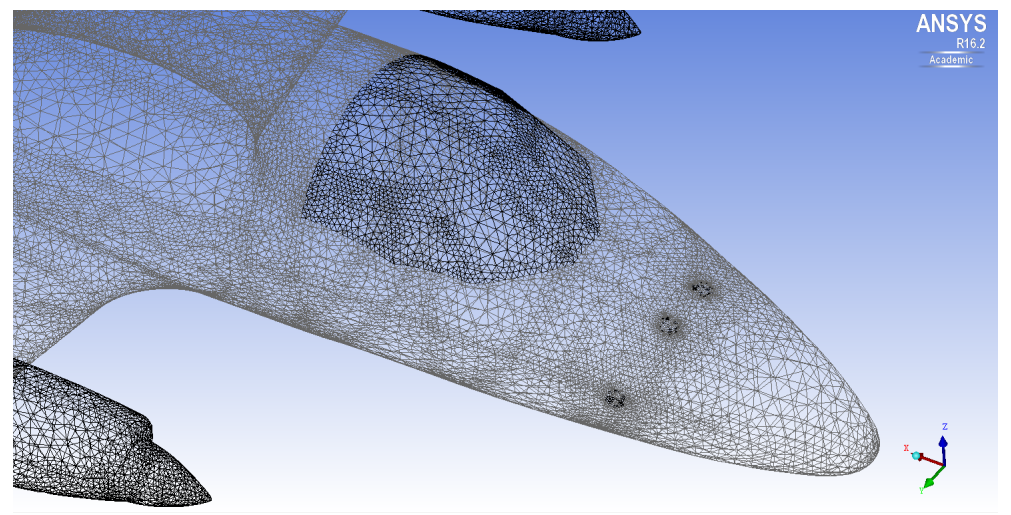

Figure 2: Full Jetstream model mesh showing increased mesh density around the flow angle vanes.

solved using the Newton-Raphson method yielding highly accurate results. The calibration and solution method in [3] did not depend on any other external factors or parameters. This ensured that errors from all other systems and equipment on-board the aircraft, other than the flow angle vanes, were eliminated. The newly devised method will apply the equations derived in [3] first, before implementing the correction factors based on the IRS bank angle reading so that the error is kept to a minimum.

The following section outlines the CFD analysis carried out in order to understand the dependency on bank angle and the derivation of the correction factors which may be applied to the already developed method found in [3].

\section{CFD Model AND ANAlysis}

The full Jetstream model, modified in [3] to incorporate the exact positions of the flow angle vanes, is utilised again here with the same mesh. Particularly fine detail was applied to the areas of the mesh around the vane locations and surrounding areas for increased accuracy. The resulting mesh has approximately 9 million elements with a maximum element size on the nose and vanes of $200 \mathrm{~mm}$ and $5 \mathrm{~mm}$ respectively, see Fig. 2. Velocity profiles and pressure coefficient plots were analysed in [3] as well as tests involving different turbulence models to validate the model as best possible and justify the selection of the mesh density and turbulence model used.

Exploiting the same model and mesh for this extended study, new case files were written for a range of far field conditions. The CFD geometry and flow direction vectors for the simulations are specified with Euler angles $\theta, \phi$, and $\varphi$, which correspond to the aircraft attitude angles $\alpha$ (angle of attack), $\beta$ (sideslip angle) and $\gamma$ (bank angle) respectively, in the aerodynamic sense. Hence, the axes were transformed using the standard direction cosine matrix for a $(1,2,3)$ Euler angle sequence [8],

$$
\mathbf{D}=\left(\begin{array}{ccc}
\cos \theta \cos \varphi & \cos \theta \sin \varphi & -\sin \theta \\
\sin \theta \sin \phi \cos \varphi-\cos \phi \sin \varphi & \sin \phi \sin \theta \sin \varphi+\cos \phi \cos \varphi & \sin \phi \cos \theta \\
\cos \phi \sin \theta \cos \varphi+\sin \phi \sin \varphi & \cos \phi \sin \theta \sin \varphi-\sin \phi \cos \varphi & \cos \phi \cos \theta
\end{array}\right),
$$

where the bank angle $\phi$ is applied first, followed by the pitch angle $\theta$, and then the yaw angle $\varphi$. Using Fluent, steady state, density based solutions were specified using the Reynolds averaged Navier-Stokes (RANS) finite volume explicit solution with second order upwind accuracy. The 


\begin{tabular}{|l|l|}
\hline Area (wing) $\left(\mathrm{m}^{2}\right)$ & 25.085 \\
Density $\left(\mathrm{kg} / \mathrm{m}^{3}\right)$ & 0.9936 \\
Enthalpy $(\mathrm{j} / \mathrm{kg})$ & 280906.5 \\
Length $(\mathrm{mean}$ chord) $(\mathrm{m})$ & 1.717 \\
Pressure $(\mathrm{Pa})$ & 78185 \\
Temperature $(\mathrm{K})$ & 274.15 \\
Velocity $(\mathrm{m} / \mathrm{s})$ & $64.31-100.3$ \\
Viscosity $(\mathrm{kg} / \mathrm{m}-\mathrm{s})$ & $1.721 \times 10^{-5}$ \\
Ratio of Specific Heats & 1.4 \\
\hline Operating Pressure $(\mathrm{Pa})$ & 78185 \\
\hline
\end{tabular}

Table 1: Table of reference values used for Fluent solver.

\begin{tabular}{|c|c|c|}
\hline$\alpha\left(^{\circ}\right)$ & $\beta\left(^{\circ}\right)$ & Mach No. \\
\hline 0 & 2 & 0.3022 \\
0 & -2 & 0.3022 \\
0 & 5 & 0.2325 \\
0 & -5 & 0.2325 \\
2.8 & 2 & 0.3022 \\
2.8 & -2 & 0.3022 \\
2.8 & 5 & 0.2325 \\
2.8 & -5 & 0.2325 \\
5.5 & 2 & 0.2480 \\
5.5 & -2 & 0.2480 \\
5.5 & 5 & 0.2015 \\
5.5 & -5 & 0.2015 \\
\hline
\end{tabular}

Table 2: Summary of CFD simulations repeated for bank angles, $\gamma=2^{\circ},-2^{\circ}, 5^{\circ}$ and $-5^{\circ}$, giving 48 cases in total.

density of air was treated as an ideal gas with the viscosity described by the Sutherland law in all cases. All airframe parts of the model were treated with wall type boundary conditions, while the domain boundaries were treated as the pressure far-field. Furthermore, all reference values were taken from flight test data and typical atmospheric conditions to be as realistic as possible, see Table 1. In general, the lift and drag monitors showed that simulations reached the accepted convergence criteria for this type of application [9], within 4000-5000 iterations. A summary of the flight conditions for the CFD simulations is given in Table 2 where all cases were repeated for bank angles, $\gamma=2^{\circ},-2^{\circ}, 5^{\circ}$ and $-5^{\circ}$. All simulations were set up assuming an altitude of 7000 feet so that the air density, pressure and temperature were $0.9936 \mathrm{~kg} / \mathrm{m}^{3}, 78185 \mathrm{PA}$ and $274.2 \mathrm{~K}$ respectively.

To analyse the CFD results, firstly a vane centre line was defined in CFD-Post according to the original scale drawings for the vane modifications. The flow direction vectors are then found at set intervals along the centre line with respect to the CFD model reference, see Fig. 3 The flow direction vectors in turn allow the local angle of attack, $\alpha_{\text {vane }}$, and local sideslip angles, $\beta_{\text {vane }}^{1}$ and $\beta_{\text {vane, }}^{2}$ to be determined at the vane locations, see the example shown in the streamline visualisation in Fig. 4. To determine the contribution of the flow angle at the individual points along the centre lines to the overall directional response of the vanes, the flow angle data is weighted based on the area of the vanes at a given length from the aircraft nose surface, again in accordance with 
the scale drawings. The vanes angular response to the local airflow can therefore be predicted, yielding a raw vane reading for each vane. These values are then compared to the free stream, or 'true', angles of attack and sideslip with which the CFD simulations were initiated.

\section{Effect of Bank Angle - Previous Calibration Method}

Considering the initial CFD analysis shown in Fig. 5 , it is seen that the raw vane readings depend linearly on the bank angle, and the error may be significant in certain flight configurations. A discussion on how the angle of attack and sideslip angle of the aircraft can obscure the vane locations from the oncoming free stream of air was given in [3]. It was concluded that when the angle of attack vane is positioned on the exposed side of the nose, ie. for negative sideslip angles, the vane over-reads the true angle of attack. Conversely, when the vane is positioned on the obscured side of the nose, the vane will under-read. Similarly for the sideslip angle vanes, in both positive and negative sideslip cases, the corresponding leading vane yielded the most accurate results with respect to the true sideslip. Therefore, it is an intuitive observation that the bank angle will affect the vanes in a similar way. For example, in the case of a negative sideslip angle and a positive angle of attack, the angle of attack vane will be far less obscured from the free stream of air when the aircraft attains either a high positive or negative bank angle (bank angle is conventionally measured positive for right wing down and negative for left wing down). This effect is depicted by the flow direction vector in Fig. 6.

The following section will now describe how the bank angle data will be monitored independently for use in an updated calibration and correction method.

\section{Development of Bank Angle Correction Method}

Results in the previous section clearly show that the raw vane readings depend linearly on the bank angle. Therefore, if the true angle of attack and sideslip are predicted using the calibration method from [3], an increasing error will be generated as bank angle increases both positively and negatively. To further quantify this dependency for each of the vanes, further analysis was conducted and regression techniques applied to the CFD data.

Firstly considering the angle of attack vane data, bank angle ( $x$-axis) was plotted against the raw angle of attack vane readings ( $y$-axis) for a fixed 'true' angle of attack and varying sideslip angles. Similarly considering the two sideslip angle vane data sets, bank angle ( $x$-axis) was plotted against the raw sideslip vane readings ( $y$-axis) for a fixed 'true' sideslip angle and varying angles of attack. Linear regression lines were plotted for each data set and their gradient and intersect determined. Since the raw angle of attack vane readings are known to depend on the bank angle and the sideslip, and the raw sideslip vane readings are known to depend on the bank angle and the angle of attack, the equations for the regression lines are of the form,

$$
\begin{aligned}
& \alpha^{\text {raw }}=m_{1} \beta \gamma+c_{1}, \\
& \beta_{1}^{\text {raw }}=m_{2} \alpha \gamma+c_{2}, \\
& \beta_{2}^{\text {raw }}=m_{3} \alpha \gamma+c_{3},
\end{aligned}
$$

where $\alpha, \beta$ and $\gamma$ are in degrees and the coefficients $m_{1}, m_{2}, m_{3}$ and $c_{1}, c_{2}, c_{3}$ are to be determined. Therefore if the raw vane readings are to equal the true angles thus,

$$
\begin{aligned}
& \alpha^{\text {raw }}=\alpha, \\
& \beta_{1}^{\text {raw }}=\beta_{1}, \\
& \beta_{2}^{\text {raw }}=\beta_{2},
\end{aligned}
$$



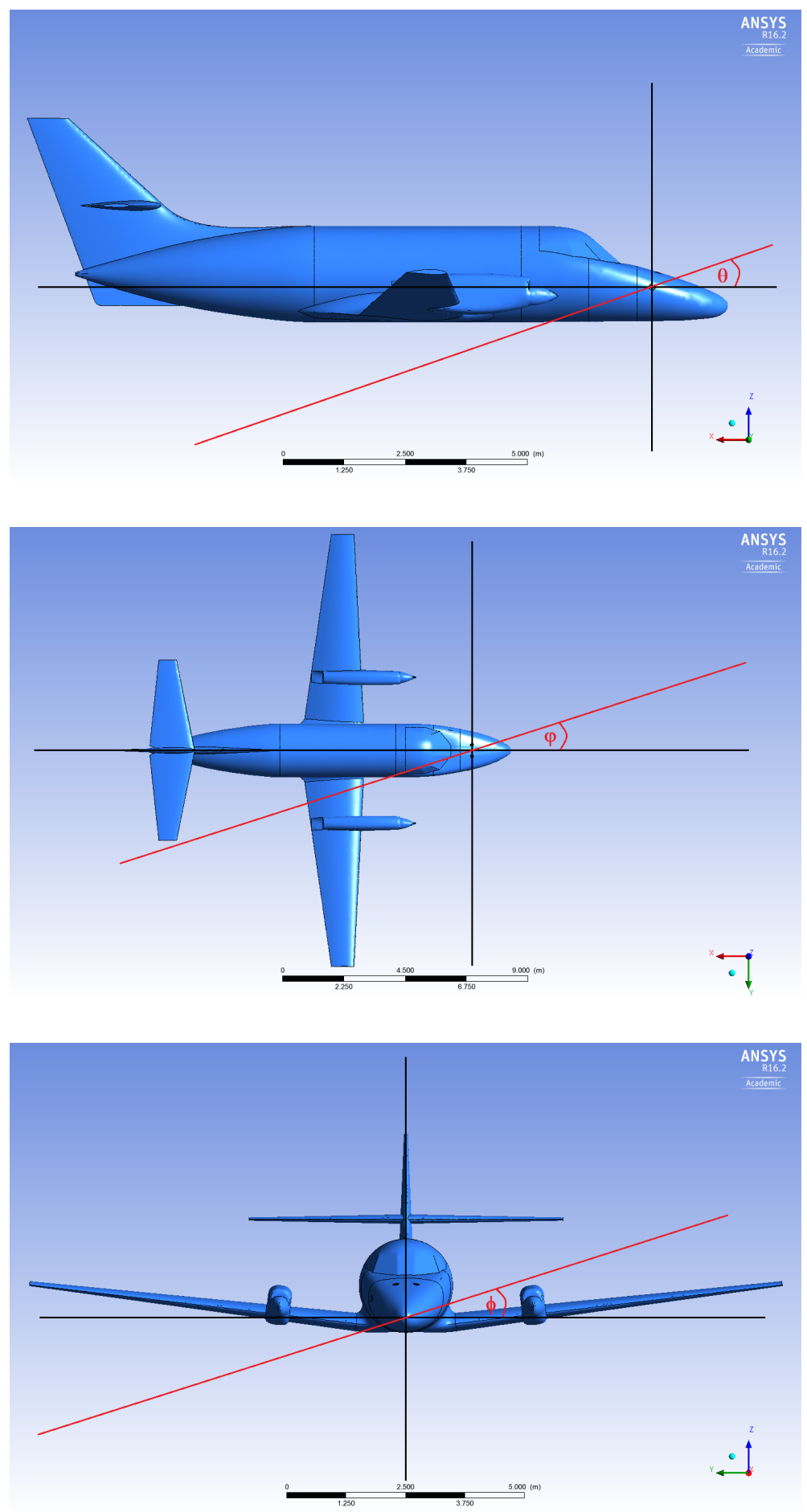

Figure 3: Schematic showing the Euler angles as defined in the CFD model set-up with respect to the aircraft reference lines (black). 

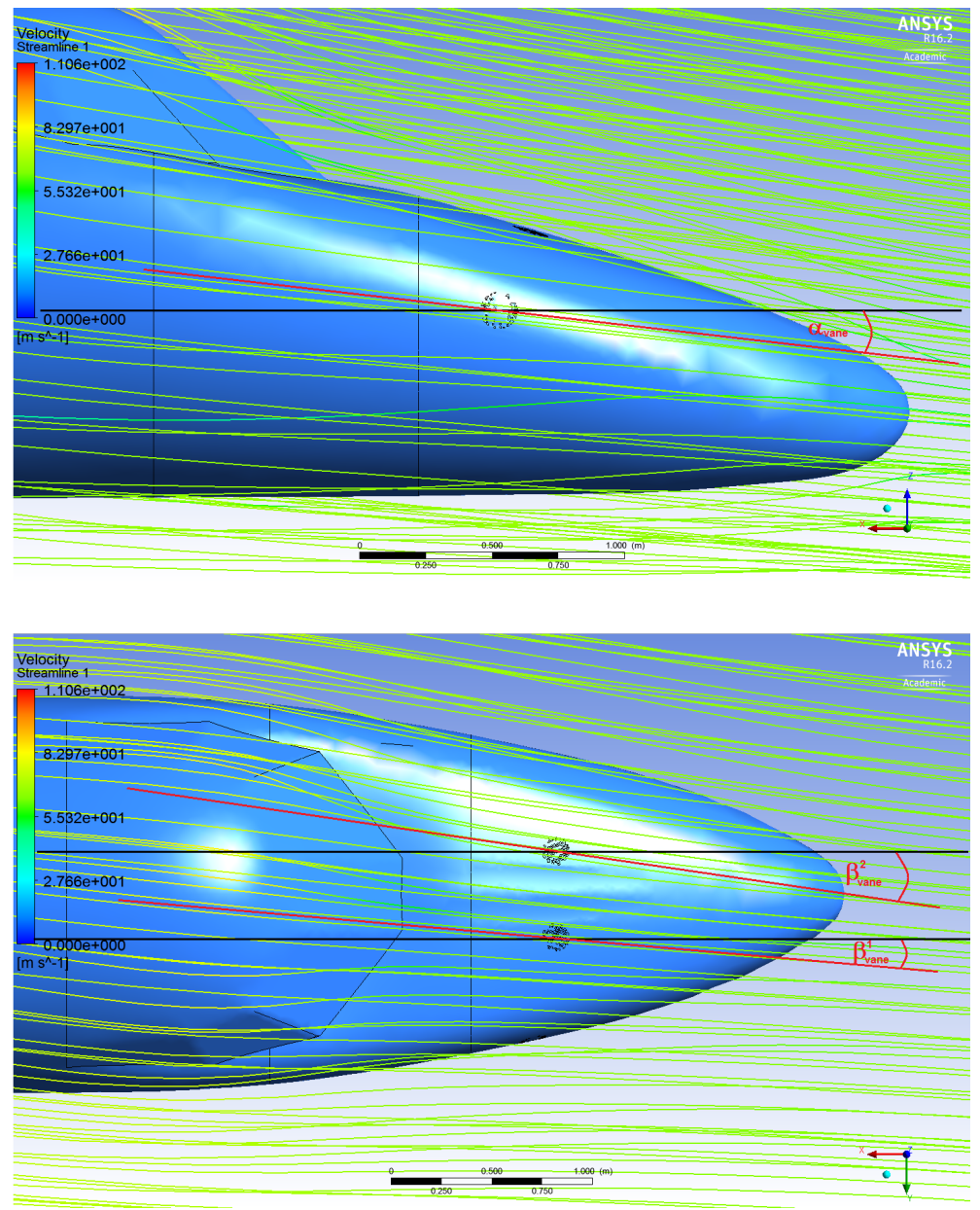

Figure 4: Streamlines showing the local flow direction at the angle of attack vane (top) and the sideslip angle vanes (bottom) for the example $\alpha=5.5^{\circ}, \beta=5^{\circ}$ and $\gamma=2^{\circ}$. 


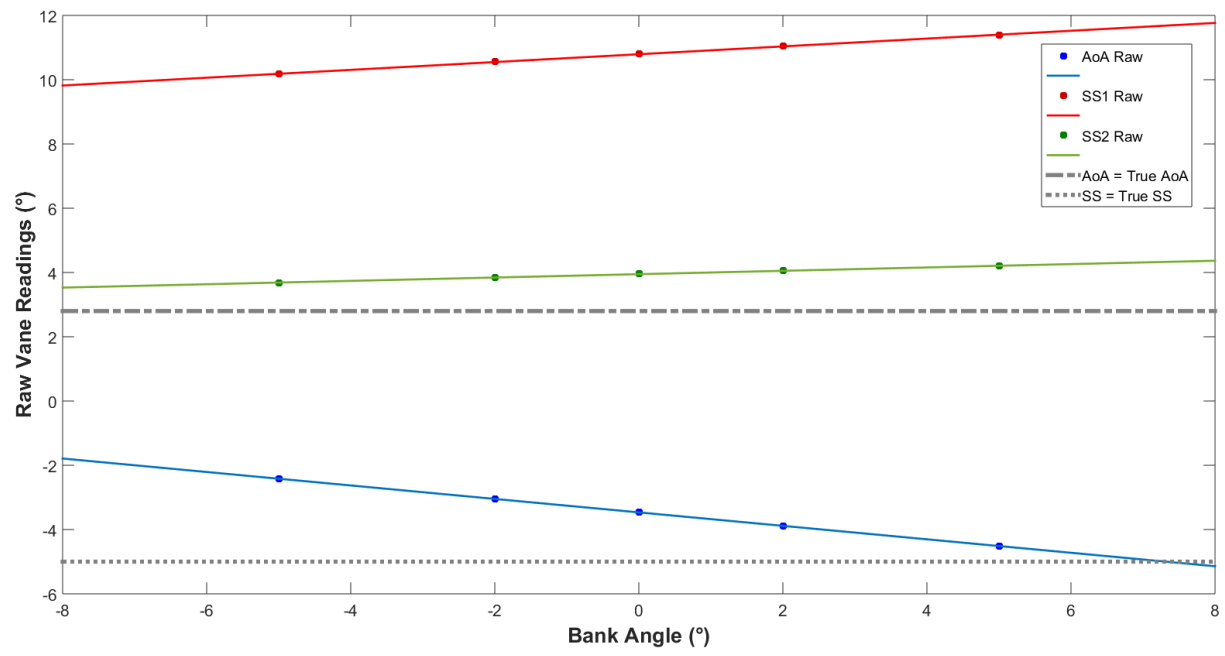

Figure 5: Graph showing the dependency of the raw vane readings on the bank angle for the specific test case where $A o A=2.8^{\circ}$ and $S S=-5^{\circ}$.

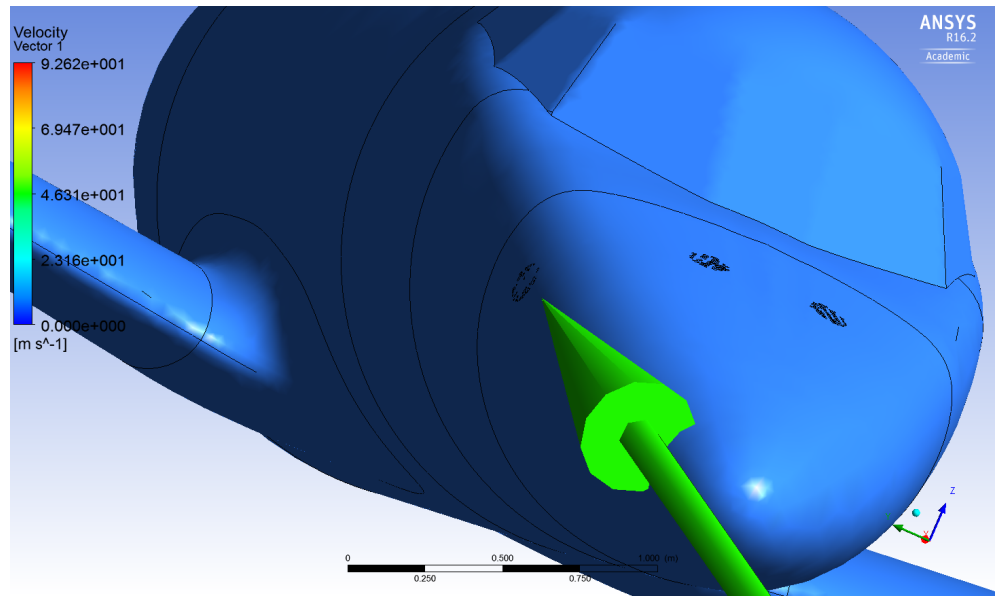

Figure 6: Flow direction vector showing how in the case of a negative sideslip angle, the introduction of a negative bank angle rotates the nose of the aircraft so that the angle of attack vane is more exposed to the on-coming free stream of air. 
then the coefficients $c_{1}, c_{2}$, and $c_{3}$ can be considered to be the outputs of the calibration method [3], ie. where bank angle is zero. The correction factors, superscript $C F$, can therefore be considered as the expressions

$$
\begin{aligned}
& \alpha^{C F}=m_{1} \beta \gamma, \\
& \beta_{1}^{C F}=m_{2} \alpha \gamma, \\
& \beta_{2}^{C F}=m_{3} \alpha \gamma .
\end{aligned}
$$

The coefficients $m_{1}, m_{2}$, and $m_{3}$ are found from averaging the gradients of the regression lines as a function of either the bank angle, $\gamma$, and the sideslip angle, $\beta$, in the case of the angle of attack vane, or the bank angle, $\gamma$, and the angle of attack, $\alpha$, in the case of the sideslip angle vanes. Fig. 7 shows how closely the gradients of the regression lines are normalised if the raw vane readings are considered as functions of two variables.

It is now seen that the difference in raw vane readings as a result of the introduced bank angle are now quantified in comparison with the cases studied in [3] where zero bank angle was considered and that the correction factors have been derived as

$$
\begin{aligned}
& \alpha^{C F}=-0.01785(\beta \gamma), \\
& \beta_{1}^{C F}=0.01632(\alpha \gamma), \\
& \beta_{2}^{C F}=0.01743(\alpha \gamma) .
\end{aligned}
$$

The correction factor equations (1), (2), and (3) may now be applied subsequently to the already verified and validated calibration method from [3]. The correction factors work to stabilise the result throughout the full range of possible bank angles.

The full solution method for the revised calibration is summarised by the following steps,

1. Equate expressions for $\beta_{1}$ and $\beta_{2}$ from the System of Equations (4) below, to find a polynomial containing only the known variables, raw sideslip vane 1 reading and raw sideslip vane 2 reading, and the unknown true angle of attack $\alpha$.

2. Solve the polynomial for $\alpha$ using the Newton-Raphson Method.

3. Replace the solution $\alpha$ into both equations for the true sideslip angle $\beta_{1}$ and $\beta_{2}$.

4. Apply the correction factor equations (1), (2), and (3) to $\alpha, \beta_{1}$ and $\beta_{2}$ respectively.

$$
\begin{aligned}
\alpha & =\frac{\text { Raw AoA Reading }+0.0001888 \beta^{3}-0.007783 \beta^{2}-0.3006 \beta+7.7993}{0.00001754 \beta^{3}-0.000435 \beta^{2}+0.01541 \beta+2.1998}, \\
\beta_{1} & =\frac{\text { Raw SS1 Reading }-0.0000497 \alpha^{3}-0.00639 \alpha^{2}+0.449 \alpha-4.3769}{0.000196 \alpha^{2}+0.01774 \alpha-1.568}, \\
\beta_{2} & =\frac{\text { Raw SS2 Reading }+0.000416 \alpha^{3}-0.00302 \alpha^{2}-0.3786 \alpha+4.262}{-0.00000549 \alpha^{3}+0.0002635 \alpha^{2}+0.01876 \alpha-1.5647},
\end{aligned}
$$

It was important that the correction factors were derived so that the angle of attack remained as a function of the sideslip and vice versa, so that the same methodology as in [3] is still valid. The method relies on the two equations for the true sideslip angle to depend only on the known raw readings and the unknown true angle of attack. These equations can therefore be solved simultaneously to find the true angle of attack before replacing into the equations for the true sideslip angles. Hence the correction factor equations (1), (2), and (3) allow a solution of the full 

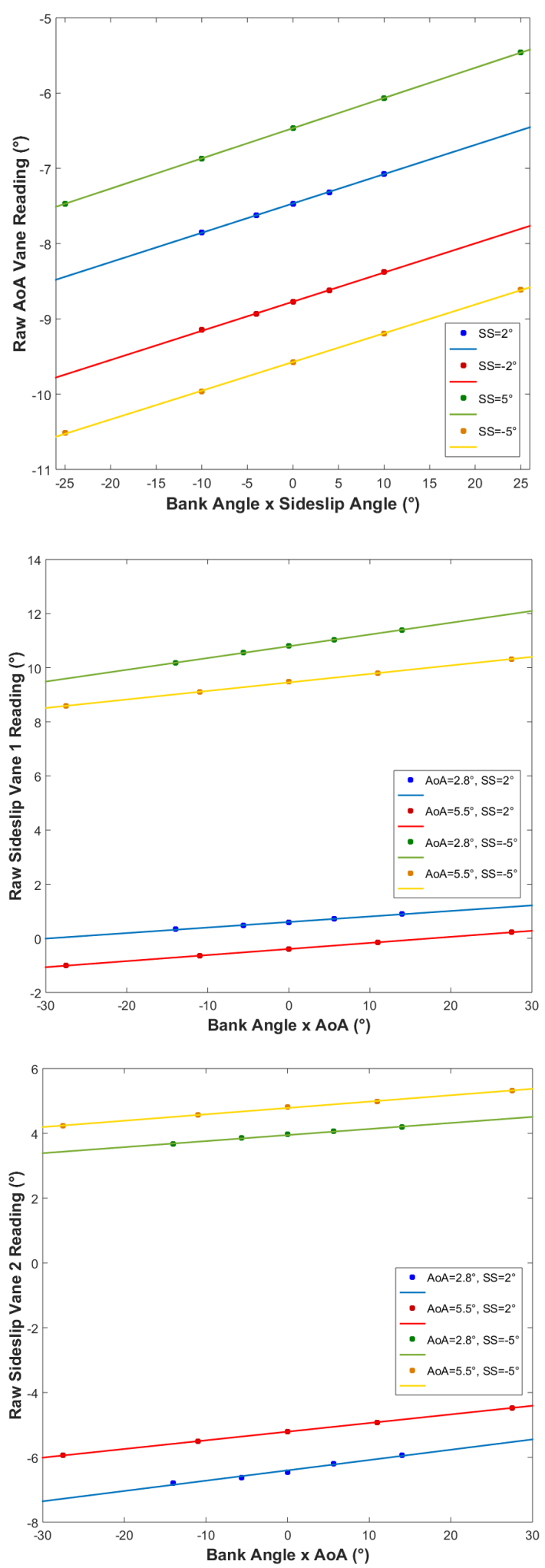

Figure 7: Graphs showing the normalised gradients of the regression lines for the raw vane data when considered as functions of two variables. 


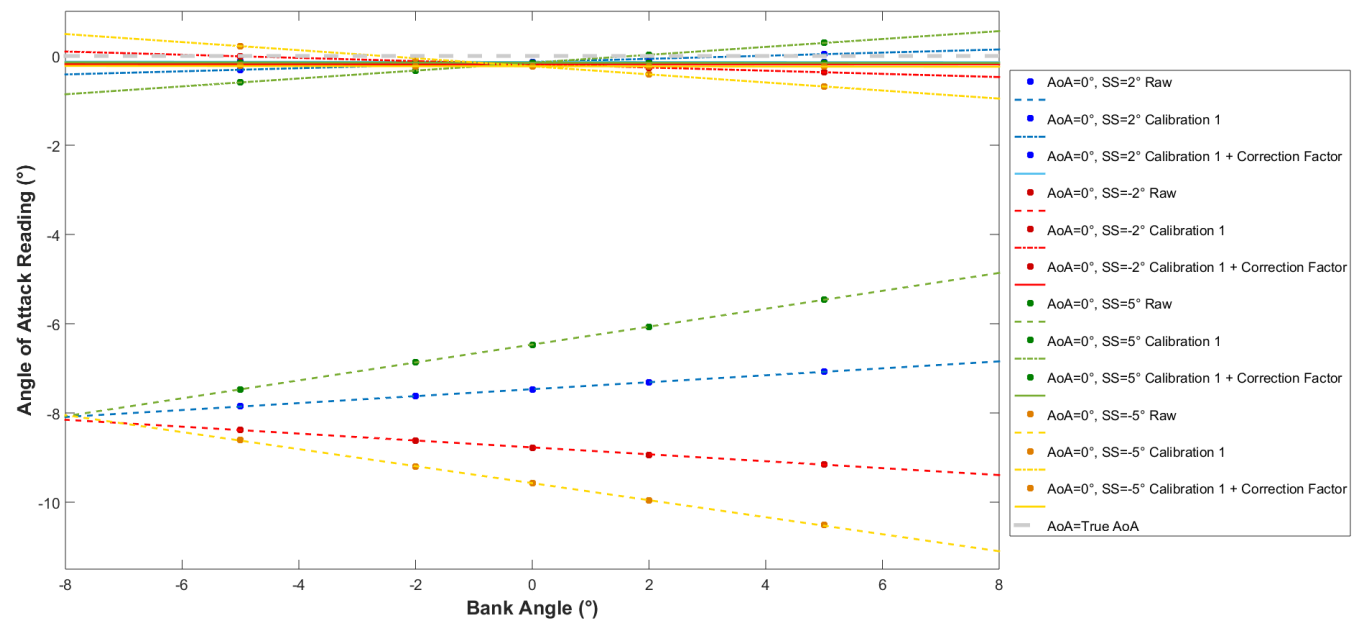

Figure 8: Graph showing the angle of attack vane reading depending on the bank angle for varying degrees of sideslip. Dotted lines correspond to the raw vane readings, dot-and-dash lines correspond to the output of calibration method [3], and solid lines correspond to the adjustment made by correction factor equation (1).

system to be obtained without the introduction of further variables or interdependencies which would make the equations impossible to solve in principle.

To illustrate the improvements made by the revised method, the example shown in Fig. 8 is for zero angle of attack and varying sideslip angles. It is clear that the method [3] and correction factor equation (1) adjust the raw angle of attack vane readings progressively closer towards the true angle of attack. The dotted lines correspond to the raw data from the angle of attack vane and shows a high dependency on the bank angle at given sideslip angles. Applying the method from [3] to the raw data yields the dot-and-dash lines which shows how the data is corrected accurately for the case when bank angle is zero, but diverges away from the true angle of attack as bank angle increases both positively and negatively. Subsequently applying the correction factors to the output of the method [3] gives the solid lines and shows how the results are stabilised throughout the range of bank angles.

Fig. 9 more clearly displays the outputs of the calibration [3] and the applied correction factor equation (1) for the same case as Fig. 8. Essentially, the revised method developed in this paper normalises the value for which the method [3] outputs for zero bank angle. As a result, it is seen that for this specific case the revised method gives results accurate to within $\approx 0.2^{\circ}$ of the true angle of attack for the entire range of sideslip and bank angles tested. All other examples for differing angles of attack showed similar levels of accuracy and uncertainty limits, see the discussion on propagation of errors in Section VI.

Now considering the sideslip angle readings, Fig. 10 displays the outputs of both sideslip vanes. Here, the method [3] and correction factor equations (2) and (3) are applied to the specific case where the sideslip angle is $2^{\circ}$ for varying angles of attack. Again it can be seen that the raw data, shown with dotted lines, has a high dependency on the bank angle, almost $2^{\circ}$ in all cases. The raw data is corrected by the method [3] to give the dot-and-dash lines which, as expected, have minimum error when the bank angle is around zero degrees. The correction factor equations (2) and (3) subsequently stabilise the data into the solid lines which are accurate with respect to the true sideslip angle to within $0.1^{\circ}$, see the more detailed view in Fig. 11. It is also worth noting 


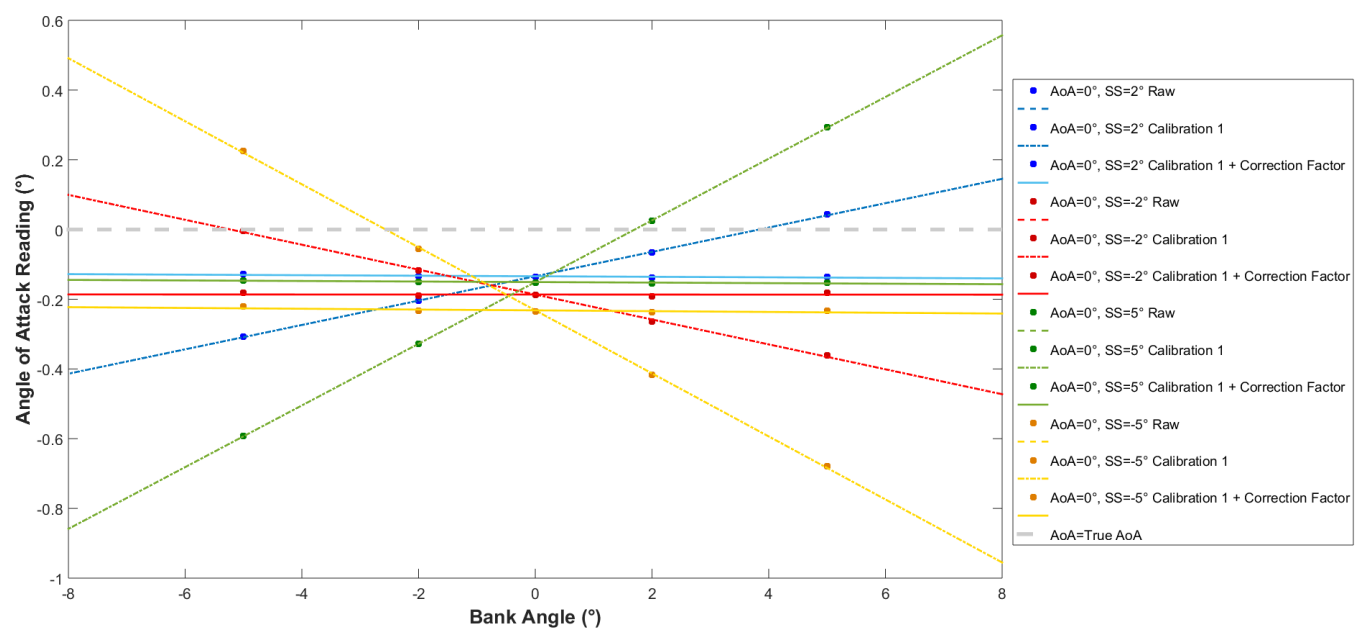

Figure 9: Rescaled view of Fig. 8 showing angle of attack outputs via calibrations method [3] and correction factor equation (1).

that for positive sideslip angle cases such as the one in this example, sideslip vane number 1 is on the leading side of the nose of the aircraft and hence why the raw data is more representative of the true value before correction. Furthermore for positive bank angles, the sideslip vanes are tilted further towards the free stream airflow and so the raw data readings become gradually closer to the true values as the bank angle is increased. Conversely, when a negative value of sideslip is considered, the opposite is true. Fig. 12 shows an example of the calibration method [3] and correction factor equation (3) applied to cases with a negative bank angle. Again, a rescaled view is shown in Fig. 13 for extra detail. As an example of this effect, the flow direction vector seen in Fig. 14 shows how in the case of a negative sideslip angle, the introduction of a negative bank angle rotates the nose of the aircraft so that the sideslip vanes are more exposed to the on-coming free stream of air.

\section{Propogation of ERror}

The error in the final output of the revised calibration method depends on the following:

1. Consistency of the raw vane readings,

2. Accuracy of the System of Equations [4] from [3] in describing the dependency of vane readings with respect to the angle of attack or sideslip angle,

3. Accuracy of solution of the System of Equations (4) via the Newton-Raphson method for $\alpha$ and $\beta$,

4. Accuracy of Bank angle measurements via IRS,

5. Accuracy of correction factor equations (1), (2), and (3) in describing the dependency of vane readings with respect to the bank angle. 


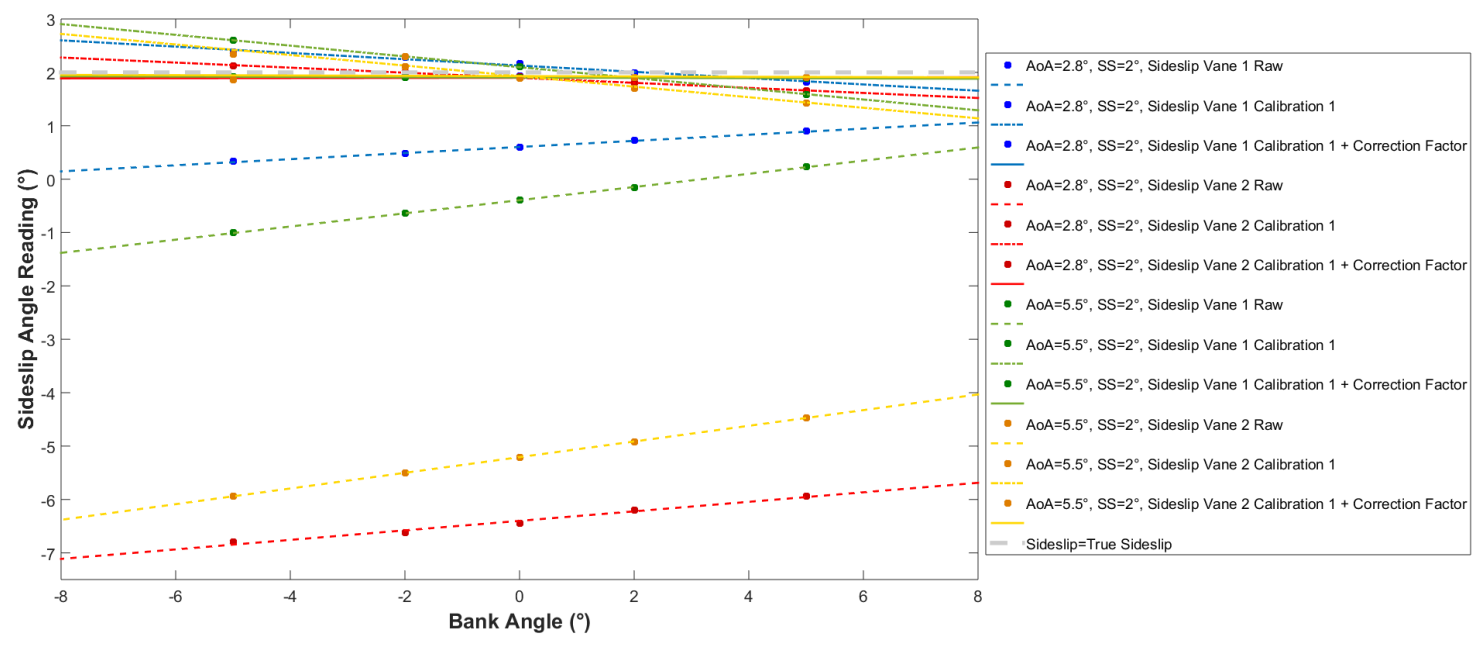

Figure 10: Graph showing the angle of attack vane reading depending on the bank angle for varying degrees of sideslip. Dotted lines correspond to the raw vane readings, dot-and-dash lines correspond to the output of calibration method [3], and solid lines correspond to the adjustment made by correction factor equation [2].

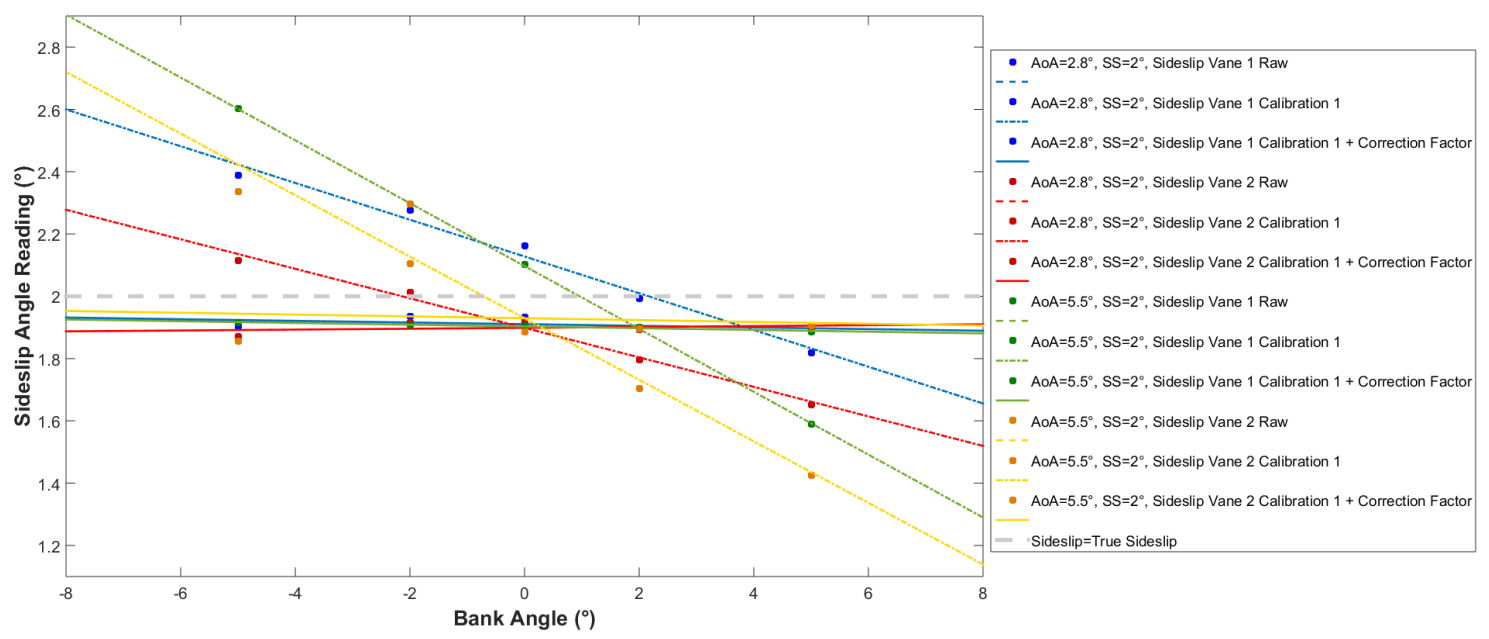

Figure 11: Rescaled view of Fig. 10 showing angle of attack outputs via calibrations method [3] and correction factor equation 2. 


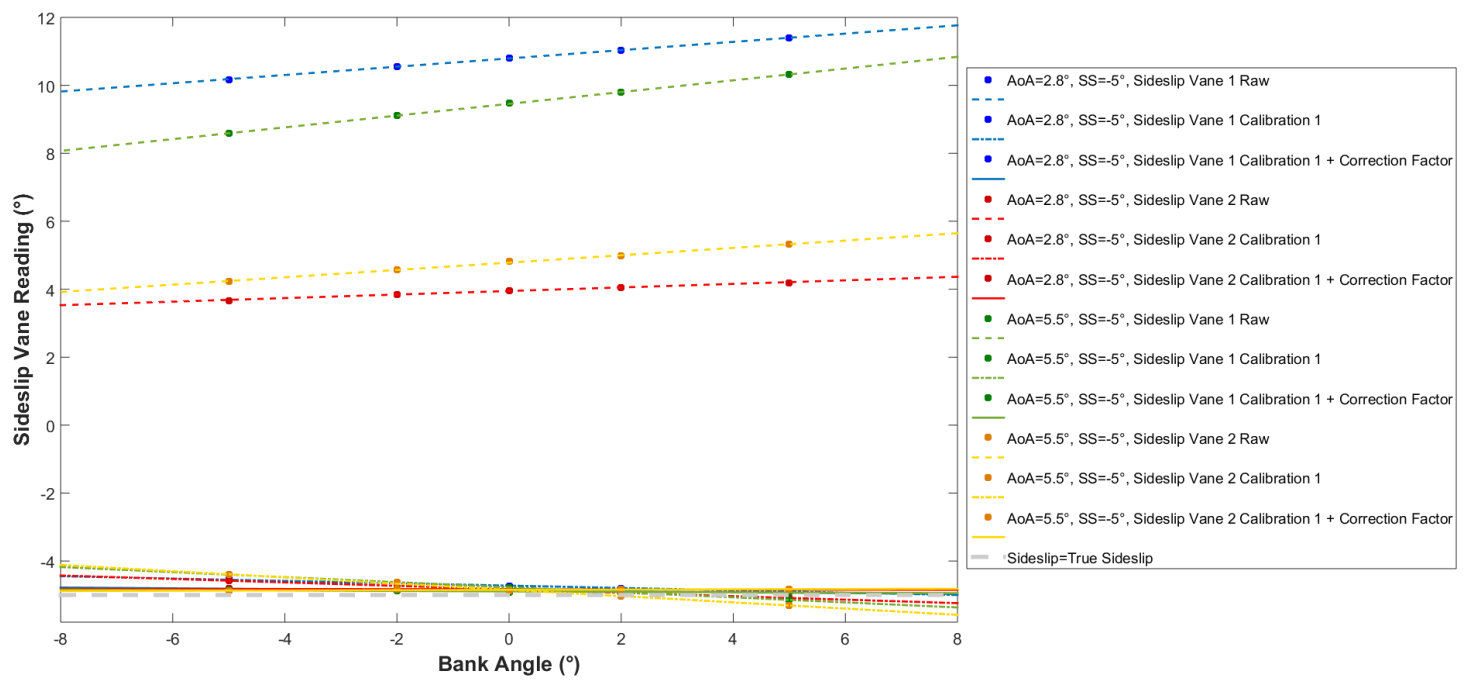

Figure 12: Graph showing the angle of attack vane reading depending on the bank angle for varying degrees of sideslip. Dotted lines correspond to the raw vane readings, dot-and-dash lines correspond to the output of calibration method [3], and solid lines correspond to the adjustment made by correction factor equation (3).

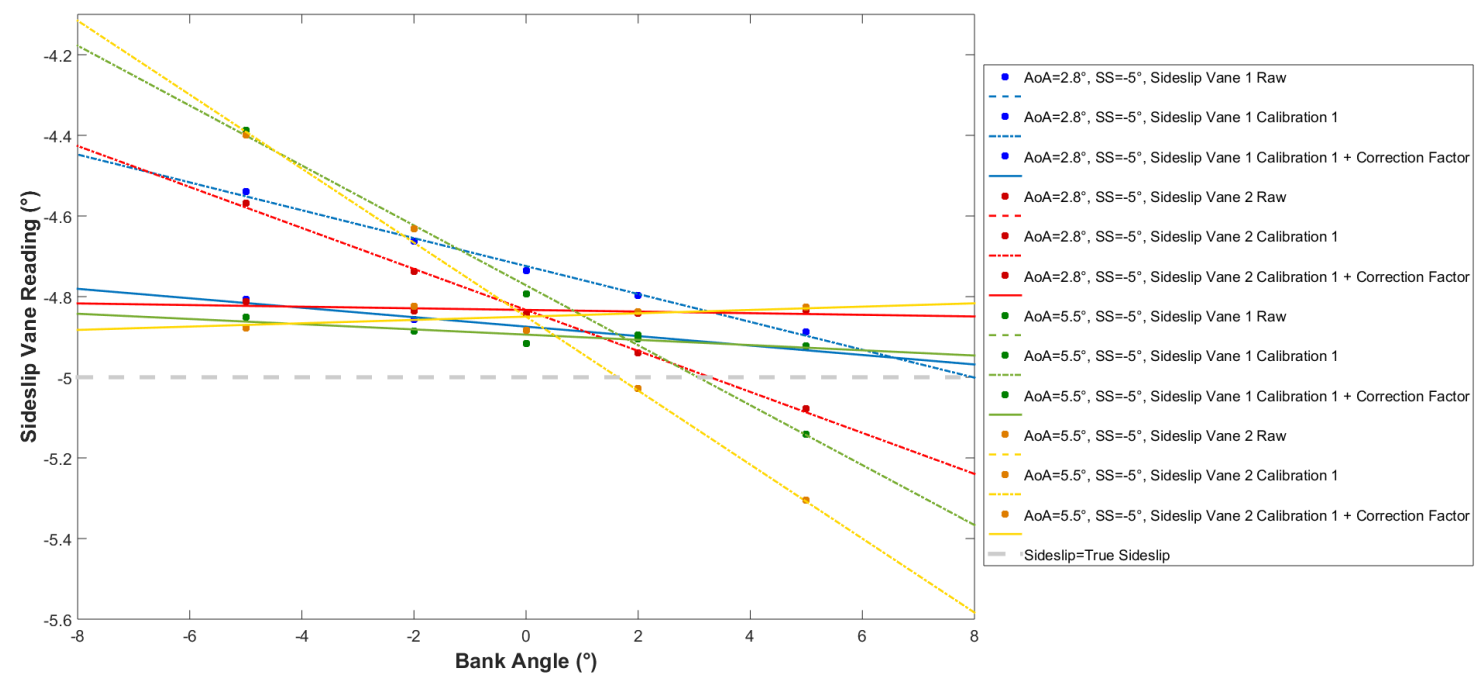

Figure 13: Rescaled view of Fig. 12 showing angle of attack outputs via calibrations method [3] and correction factor equation (3). 


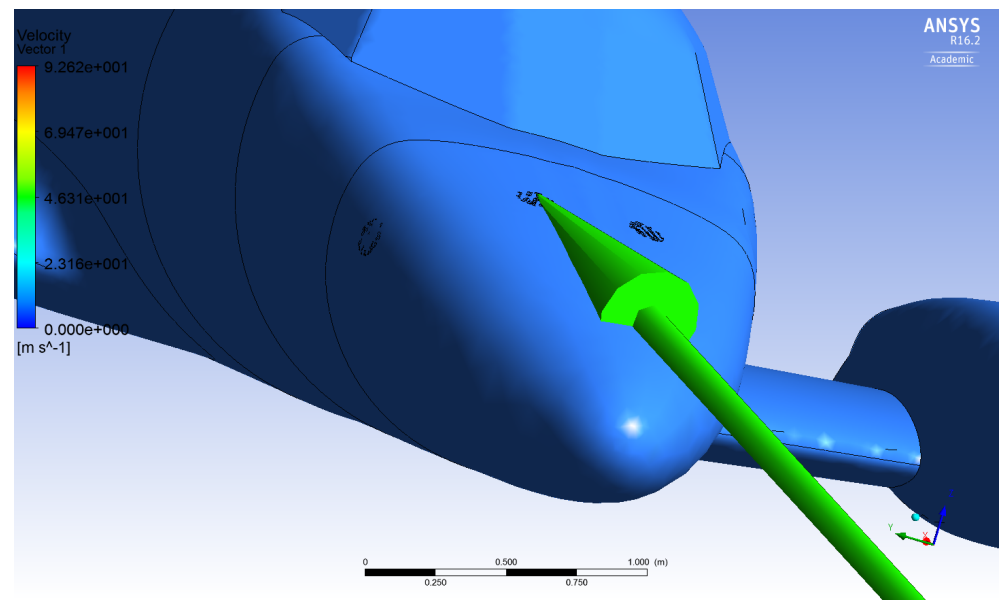

Figure 14: Flow direction vector showing exposure of sideslip angle vane 1 to the on-coming free stream of air under specific flow conditions.

Following the variables throughout the method it is seen that the output variables are functions of the following

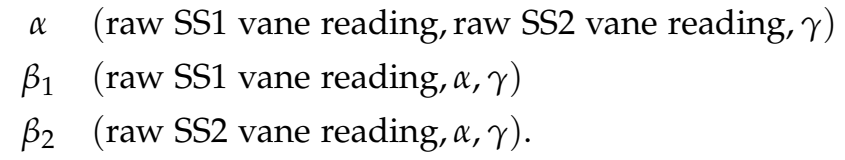

It is important therefore to assess how errors in the initial measurement of the individual variables propagate through the method to the final output. Monte-Carlo simulations were run on each of the input variables, raw angle of attack reading and both raw sideslip vane readings, to determine the sensitivity of the final output. Fig. 15 shows how the percentage error in the final calibration output increases as the error in initial measurements increase up to $\pm 2^{\circ}$, for the specific case where angle of attack is $2.8^{\circ}$, sideslip is $2^{\circ}$ and bank angle is $2^{\circ}$. As shown in the previous section, the calibration method is stable for all flight conditions considered and hence the relationship between the initial measurement error and the error in the final output is approximately linear. It is seen that the angle of attack output is much less susceptible to errors in the input variables than the sideslip outputs. This is because the angle of attack is calculated first and then used in the calculation of the sideslip angle, amplifying any errors.

However, flight tests in [3] showed that the IRS has a $95 \%$ confidence interval of $\pm 1.4^{\circ}$ and that vane reading errors are negligible. Therefore, considering an angle of attack and sideslip angle range of $+15^{\circ}$ to $-15^{\circ}$ with these assumptions, the output of the calibration method has a $95 \%$ confidence interval of less than $\pm 0.4^{\circ}$.

\section{Solution Method via MATLAB Function}

The MATLAB function written in [3] has been modified to apply the correction factors (1), (2) and (3) to the final output of the original calibration. The updated errors of the method are also calculated and printed to the screen. Appendix contains the code in full along with a flow chart of the code structure. 

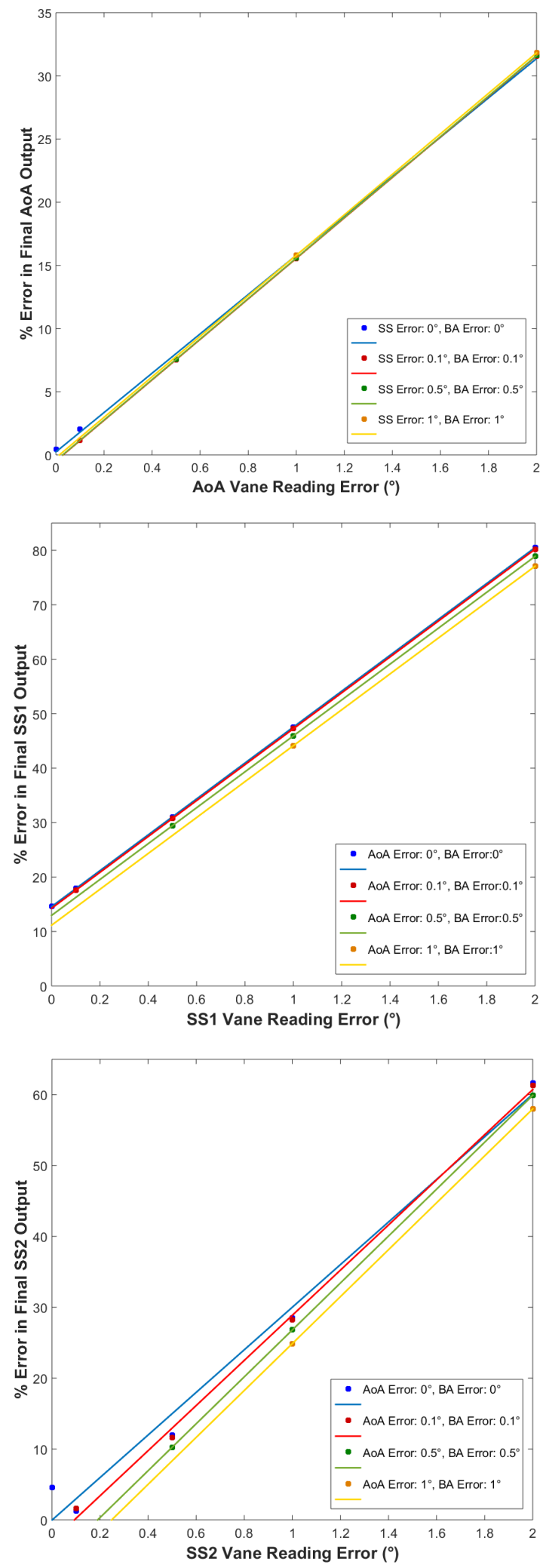

Figure 15: Propagation of input errors throughout the calibration method and correction. 
The correction factors are obviously greater in magnitude for higher bank angles, however, they are still worth applying for bank angles close to zero since the time taken for the added calculation is negligible. Furthermore, the correction factors will always shift the data points closer to the true angle of attack, apart from when the bank angle is zero in which case the output of calibration [3] will remain the same.

The revised code means that in flight, close to real-time readings are possible with an average error of less than $0.5^{\circ}$ for both angle of attack and sideslip angle. On average, five data samples per second is the maximum resolution, however, the resolution may be increased with a more powerful computer. It is clear that the percentage improvement on the method [3] is much greater for higher bank angles. For example in the case where $\mathrm{AoA}=2.8^{\circ}, \mathrm{SS}=-5^{\circ}$, and $\mathrm{BA}=5^{\circ}$, the correction factor reduces the error in angle of attack prediction from $0.37^{\circ}$ to $0.15^{\circ}$, an improvement of over $50 \%$, but the total sideslip error remains roughly the same.

\section{Conclusions}

The aim of this paper was to extend the previous study, where only angle of attack and sideslip angle cases were considered, to definitively understand the behaviour of the flow angle vanes on a BAe Jetstream 3102 for all possible flight conditions including a range of bank angles. Previously, a calibration method to convert raw angle of attack and sideslip angle readings into true values was derived but did not consider the effect of bank angle. Here, the method has been revised to include a set of correction factors to deal with the introduction of bank angle.

From initial test cases, it was seen that the flow angle vanes are not only affected by the aircraft angle of attack and sideslip, but also the bank angle. This is due to the rotation of the nose exposing and obscuring the vane locations from the free stream of airflow in certain flight conditions. Detailed CFD analysis was therefore undertaken to fully understand the relationship between the local flow direction at the vanes and the bank angle of the aircraft.

A full matrix of CFD simulations were performed to gather an encompassing set of data. Using post processing techniques, analysis of the local flow around the vane locations was undertaken to predict the directional response of the flow angle vanes in flight. Using regression techniques, a system of correction factors was derived as functions of the bank angle. Applying the correction factors to the previous zero bank angle method, ensured a stabilising effect is observed over the whole range of flight conditions yielding highly accurate results for all bank angles. The calibration method, solution, and corresponding MATLAB code have been designed so that it can be implemented using the current systems on the Jetstream to receive close to real time readings. The new method reduces error as a result of external systems and also improves the resolution for data acquisition during laboratory flights. Utilising the proposed method, the error in angle of attack and sideslip angle may be reduced by up to $2.5^{\circ}$ and $1.5^{\circ}$ respectively for high bank angles. Furthermore, by using Monte-Carlo simulations, uncertainty analysis indicated that raw vanes reading errors should be below $\pm 0.1^{\circ}$ to ensure that total calibration errors are restricted to less than $2 \%$ for angle of attack and $5 \%$ for sideslip angle. 


\section{A. ApPEndix}

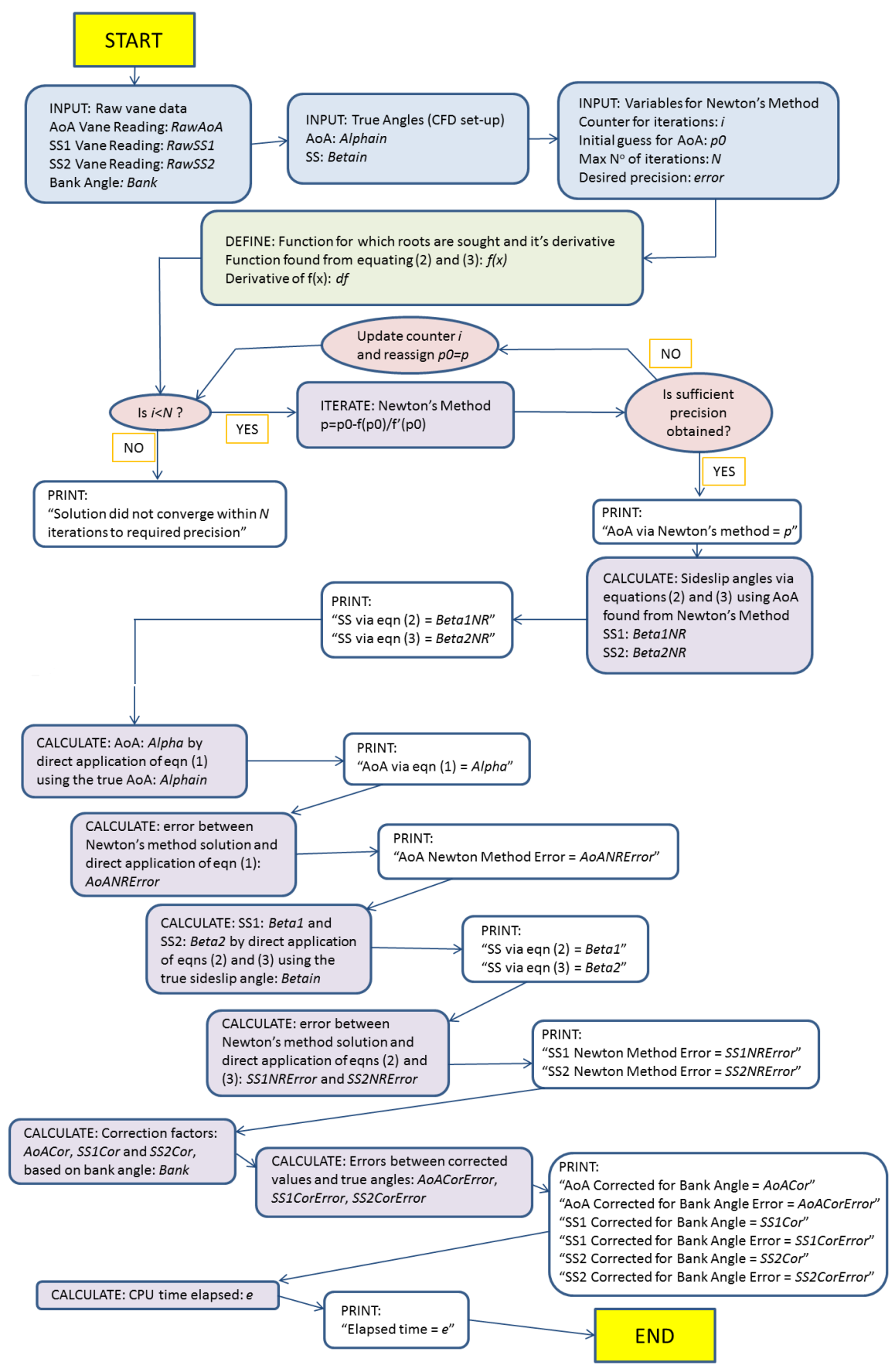

Figure A.1: Flowchart outlining the MATLAB code structure. Code variables are referred to in italics. 


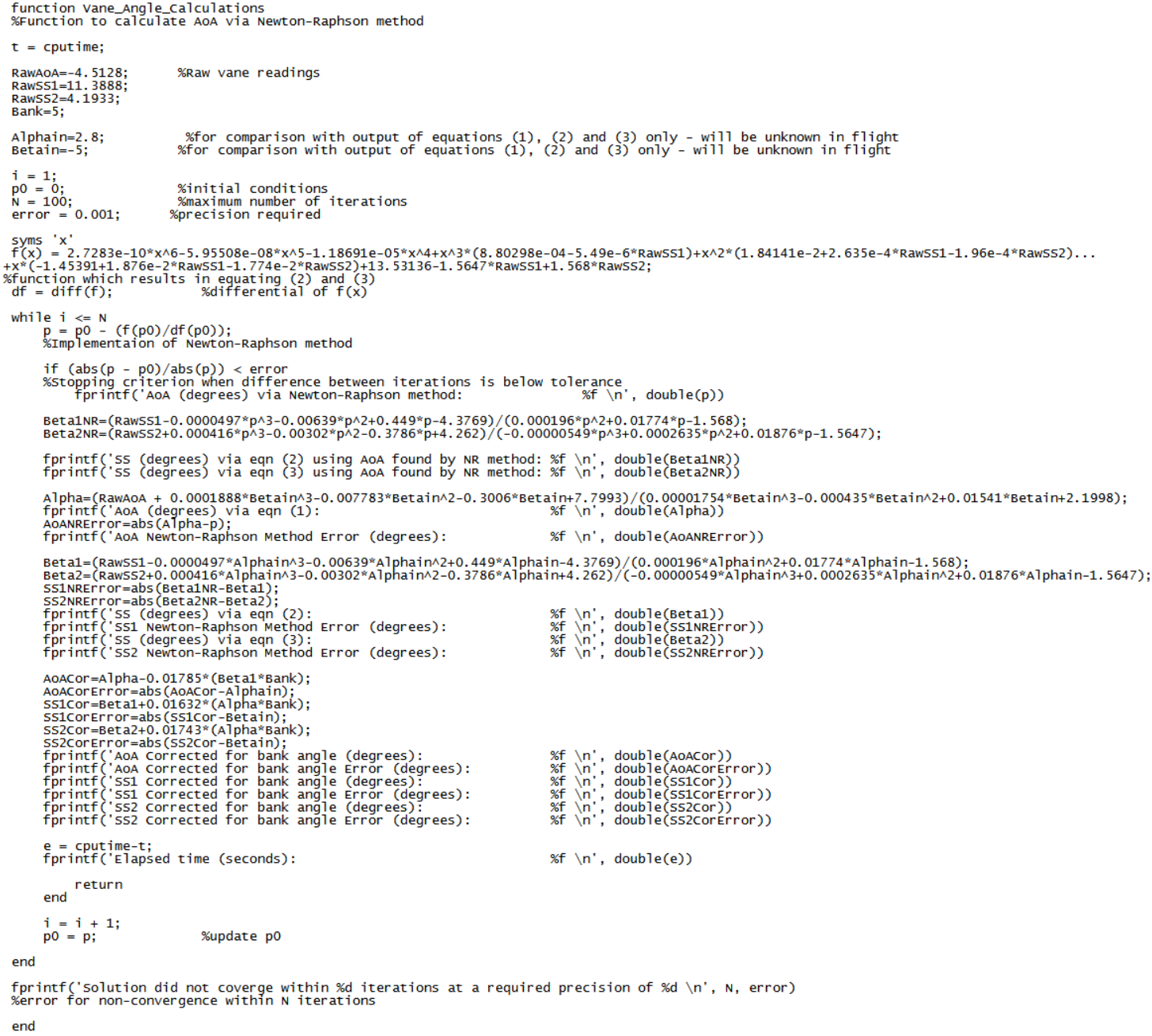

Figure A.2: Updated MATLAB function 'JetstreamCorrectionFactor'. 


\section{REFERENCES}

[1] J. A. Lawford and K. R. Nippress. Calibration of air-data systems and flow direction sensors. Advisory Group for Aerospace Research and Development (AGARD) Flight Test Techniques Series, 1(AG-300), 1984.

[2] G. M Sakamoto. Aerodynamic charachteristics of a vane flowangularity sensor system capable of measuring flightpath accelerations for the mach number range from 0.40 to 2.54 . NASA Technical Note, (TN D-8242), 1976.

[3] C. J. Bennett, N. J. Lawson, J. E. Gautrey, and A. Cooke. CFD simulation of flow around angle of attack and sideslip angle vanes on a bae jetstream 3102 - part 1. Submitted to Aerospace Science and Technology, 2016.

[4] J. D. Anderson. Computational Fluid Dynamics - First Edition. McGraw-Hill Education, New York, USA, 1995.

[5] C. D. Perkins, D. O. Dommasch, and E. J. Durbin (Eds.). Flight Test Manual - IV. Instrumentation Systems - AGARD. Pergamon Press, New York, USA, 1959.

[6] S. Kyle. Roll angle in 6DOF tracking. Charlotte-Concord, USA, 2008. Coordinate Metrology Systems Conference.

[7] J. G. Webster and H. Eren (Eds.). Measurement, Instrumentation and Sensors Handbook - Second Edition. CRC Press, Florida, USA, 2014.

[8] M. V. Cook. Flight Dynamics Principals - Second Edition. Elsevier, Oxford, UK, 2007.

[9] P. J. Roache. Verification and Validation in Computational Science and Engineering. Hermosa, New Mexico, USA, 1998. 
2017-03-16

CFD simulation of flow around angle of attack and sideslip angle vanes on a BAe Jetstream 3102 - Part 2

Bennett, Christopher J.

Elsevier

C.J. Bennett, N.J. Lawson, J.E. Gautrey, A. Cooke, CFD simulation of flow around angle of pÿattack and sideslip angle vanes on a BAe Jetstream 3102 Part 2, Aerospace Science and Technology, Volume 68, September 2017, Pages 577-587

http://dx.doi.org/10.1016/j.ast.2017.03.014

Downloaded from Cranfield Library Services E-Repository 